\title{
L’objecció de consciència durant el franquisme i la Transició. Dissidència política i xarxa de suport
}

\author{
CARLOS ÁNGEL ORdÁs \\ Centre d’Estudis sobre les Ėpoques Franquista i Democràtica \\ de la Universitat Autònoma de Barcelona (Espanya) \\ orcid.org/0000-0002-2927-5281
}

Presentació: 14 set. 2016 | Acceptació: 18 oct. 2016 | Publicació: 15 des. 2016

Citació recomanada: ORDÁs, Carlos Ángel. «L'objecció de consciència durant el franquisme i la Transició. Dissidència política i xarxa de suport». Franquisme \& Transició. Revista d'Història i de Cultura 4 (2016): 89-125. doi: http://dx.doi.org/10.7238/fit.voi 4.3095

Resum: La resistència al servei militar durant el franquisme va començar a la darreria de la dècada dels cinquanta manifestant una mena de dissidència religiosa. Més tard, durant els anys setanta, aquesta resistència va transformar-se i es va consolidar en dissidència política i ideològica contra la dictadura. L’objecció de consciència fins al final de la dècada dels setanta va ser minoritària i poc coneguda. No obstant això, els objectors van aconseguir una important incidència política i social, a causa, sobretot, de l'estratègia d'assumir la repressió com a forma de deslegitimació i denúncia. I també gràcies a la creació d'una xarxa de suport nacional i internacional que va potenciar enormement l'acció dels objectors.

Paraules clau: objecció de consciència, no-violència, pacifisme, moviments socials

\section{Conscientious objection during the Franco dictatorship and the transition: Political dissent and support networks}

Abstract: Conscientious objection during the Franco dictatorship began at the end of the fifties as an expression of a form of religious dissidence. During the seventies, this resistance became consolidated in political and ideological dissent against the dictatorship. Until the end of the seventies, conscientious objection was a fringe and little-known activity. However, objectors had an important political and social effect, mainly due to their strategy of converting repression into a form of delegitimization and complaint, and also owing to 
the creation of a network of national and international support that greatly

enhanced the objectors' activities.

Keywords: conscientious objection, nonviolence, pacifism, social movements

\section{Introducció}

La resistència al servei militar obligatori ha estat una constant històrica des que el servei armat a la nació fou prescrit a tota la població masculina durant el segle xIx en l'Europa occidental. Les formes legals i illegals d'evadir aquesta obligació van ser constants en cada reemplaçament. A més, eren focus de fortes tensions en el món rural i a les ciutats, a causa dels riscos que l'entrenament militar i, sobretot, la participació en episodis bèllics implicaven per a la integritat física. Davant les resistències de la població, els diversos estats imposaven càstigs severs a aquelles persones que tractessin d'eludir el servei d'armes i, alhora, promocionaven els valors i honors militars.

Més enllà de la lògica voluntat de mantenir la pròpia integritat física, des del mateix segle xix la resistència al servei militar va carregar-se d'arguments, sobretot de dos tipus: religiosos, lligats a branques del cristianisme, i polítics, vinculats a grups socialistes i especialment anarquistes. En aquest últim cas, són molt coneguts els debats de la Segona Internacional sobre la guerra i les resistències dels grups a aquesta i a un possible conflicte internacional. En el primer cas, algunes sectes, com ara els quàquers, els mennonites i els testimonis de Jehovà, es van negar en tot moment a respondre davant les obligacions militars, de manera que des de posicions polítiques i religioses ja es projectaven formes de rebuig al servei militar obligatori.

El salt definitiu cap a la creació de grups de resistents a la guerra va produir-se arran de la Primera Guerra Mundial, quan van sorgir les primeres coordinadores internacionals de refractaris. Entre aquestes organitzacions destaquen la War Resisters International (d'ara endavant, WRI) i la International Fellowship of Reconciliation (IFOR). En les dècades posteriors del segle xx, la resistència al servei militar es va anar estenent per diversos països europeus i als Estats Units i el Canadà. Van ser anys en els quals es va desenvolupar la denominada «objecció de consciència», molt 
lligada a les motivacions polítiques i religioses esmentades, i la doctrina de la no-violència, durant la segona meitat del segle xx. L'objecció de consciència va anar obrint-se pas fins a arribar a articular tot un moviment social en països com Bèlgica, Holanda, França i Itàlia. A Espanya això també va passar, tot i que el règim dictatorial que va aconseguir implantar-se des del 1936 va endarrerir substancialment l'aparició de l'objecció de consciència i el posterior reconeixement.

\section{El difícil context per a la resistència al servei militar obligatori durant el franquisme}

La dictadura franquista va ser, sens dubte, el condicionant principal que explica l'aparició tardana de l'objecció de consciència al territori espanyol. No obstant això, malgrat el difícil context polític i social per a la resistència al servei militar, van començar a aparèixer persones que es van negar a realitzar les obligacions militars. Aquests pioners van plantejar al règim un cas clar de dissidència, que, com veurem més endavant, va fonamentar-se primer en una qüestió religiosa ${ }^{1}$ i durant la dècada dels setanta en plantejaments del tot polítics i ideològics.

La resistència al servei militar va ser, per la mateixa naturalesa del règim, un desafiament polític i una manifestació de dissidència, de manera que la resposta sempre fou categòricament repressiva. La lògica de funcionament de la dictadura suposava una estructura jeràrquica de presa de decisions, per la qual cosa els canvis i les modificacions eren projectats cap a una sola direcció — de dalt a baix—, sense la possibilitat d'invertir-ne l'ordre. Qualsevol intent de pretendre canviar o subvertir aquesta dinàmica topava amb la resposta repressiva ferma i taxativa de l'Estat.

Com és sabut, durant el franquisme no hi hagué un espai propici per a la generació de cap tipus de moviment social, atès que precisament el règim s'havia desenvolupat en contra d'aquests grups, en especial de l'obrer. ${ }^{2}$

1 La dissidència religiosa tenia, òbviament, connotacions polítiques per la naturalesa del règim, que convertia qualsevol tipus de dissidència en una desafecció frontal cap a si mateix i, per tant, en un assumpte també d'ordre polític.

2 C. Molinero i P. Ysàs, Productores disciplinados y minorías subversivas (Madrid: Siglo Veintiuno de España Editores, 1998).

FRANQUISME \& TRANSICIÓ 4 (2016) ISSN 2014-511X PUNCTUM, UNIVERSITAT OBERTA DE CATALUNYA \& FUNDACIÓ CARLES PI I SUNYER 
El règim imposat després de la victòria del bàndol colpista en la Guerra Civil es va consolidar sobre la base d'una voluntat totalitària que va gaudir de l'impuls i del suport de sectors feixistes i catòlics, i, a més, va desplegar una política repressiva, una condició sine qua non per garantir la submissió de tota la societat. En definitiva, «el franquisme va voler tenir la societat sotmesa a un control rigorós, de manera que no existissin espais on poguessin desenvolupar-se actituds i accions que permetessin l'aparició i l'extensió de dissidències $\mathrm{i}$, molt menys encara, de dissentiments». ${ }^{3}$ La violència repressiva del règim va ser contínua des de l'origen sagnant (l'estiu del 1936) fins a les últimes execucions (el setembre del 1975 i més enllà). El nou marc legal i les noves institucions creades pel franquisme van servir perquè «en lo sucesivo nadie ose desviarse de una rígida disciplina social».4 Així doncs, en un sector important de la societat espanyola d'aquells anys és normal advertir un distanciament envers la crítica política i social, que cal interpretar, també, com una actitud de prudència i no tan sols com a passivitat i apatia política. Aquest va ser un dels èxits indiscutibles de l'aparell repressiu franquista, que sempre va tenir la voluntat de paralitzar extensos sectors de la societat per mitjà de la por.

D’altra banda, la dissidència que implicava resistir-se a fer el servei militar xocava frontalment contra el fort militarisme de la dictadura. Sense necessitat d'entrar en el debat sobre la naturalesa del règim, és innegable la marcada influència que hi exercia la institució castrense, la qual va suposar alhora una forta promoció del militarisme, tant de les seves pràctiques com dels seus valors. Aquest component castrense es va desenvolupar especialment des de dos pilars del Nuevo Estado: l'exèrcit i la Falange; però també des de l'Església catòlica espanyola, que, sobretot en les primeres dècades de la dictadura, va mostrar sense reserva una gratitud a l'exèrcit revoltat i vencedor de la Guerra Civil.

El militarisme va formar part de la idiosincràsia del franquisme. Deixant ara de banda la major o menor incidència dels militars en el règim, és determinant que es traslladessin els valors castrenses a la societat es-

3 C. Molinero i P. Ysàs, Els anys del PSUC. El partit de l'antifranquisme (1956-1981) (Barcelona: L'Avenç, 2010), 344.

4 Ley de Rebeldía Militar (1943), dins Molinero \& YsÀs, Productores disciplinados y.., 259. 
panyola, tal com ho demostra el fet que els principis militars figuressin explícitament en l'ordenament jurídic al més alt nivell, segons l'article setè del Fuero de los Españoles del 17 de juliol de 1945: «constituye título de honor para los españoles el servir a la Patria con las armas. Todos los españoles están obligados a presentar este servicio cuando sean llamados con arreglo a la ley». En paraules de Joaquim Lleixà, «el régimen franquista dio lugar a una eclosión de militarismo: un militarismo actualizado, de signo contrarrevolucionario, que se manifestó, por lo pronto, en la militarización de las relaciones sociales, políticas y culturales en el llamado Estado nuevo [...]. Así, los valores que venían siendo característicos del aparato militar español, sus pautas de organización y hasta su organización misma, sus fines relativos a la guerra contra el enemigo interior, llegarían a impregnar el conjunto del Estado y la sociedad civil. [...] la eclosión militarista aludida se manifestó, en lo relativo a la influencia política del Ejército, en la dirección del poder público al aparato militar». ${ }^{5}$ Així doncs, els valors militars i els seus principis estructurals van ser potenciats de manera que «las ideas de jerarquía y autoridad son transmitidas en la escuela y en el Ejército, como si España fuera un gran regimiento donde se imparten valores y virtudes militares y se exige absoluta obediencia y estricta disciplina». ${ }^{6}$ Durant el franquisme es produeix «un reforzamiento del valor de la autoridad y del autoritarismo, de la configuración vertical y jerárquica de la sociedad y de la política. Se hace insistencia especial en la valoración positiva de la obediencia ciega y total, en la disciplina, sumisión, resignación, hincapié en los deberes y obligaciones individuales; desvalorización de los derechos y de su eventual reivindicación; exaltación del sentido militar y religioso de la vida».7

Altrament, un dels objectius de la dictadura era controlar la sociabilitat de la població i la seva socialització. No sempre ho va aconseguir, però va disposar d'espais per fer-ho. Un d'aquests espais va ser, sens dubte, el temps que els joves havien de passar al servei militar. L'exèrcit exercia un

5 J. LleIXÀ, Cien años de militarismo en España (Barcelona: Anagrama, 1999), 143-144.

6 M. Aguilar Olivencia, El ejército español durante el franquismo. Un juicio desde dentro (Madrid: Akal, 1999), 44.

7 G. Cámara Villar, Nacional-catolicismo y Escuela. La Socialización Política del Franquismo, 1936-1951 (Jaén: Hesperia, 1984), 332.

FRANQUISME \& TRANSICIÓ 4 (2016) ISSN 2014-511X PUNCTUM, UNIVERSITAT OBERTA DE CATALUNYA \& FUNDACIÓ CARLES PII SUNYER 
paper preeminent en la socialització de la joventut masculina, ja des de la postguerra. Dins d'aquest paper destacava de manera especial el caràcter coactiu del servei militar, sobre la base de com estava formulat: la institució militar desenvolupava un paper primordial en el control social mitjançant l'adoctrinament polític durant el servei militar, que, tal com se suposava, afavoria els processos de reconstrucció nacional, desarrelament territorial i lingüístic, i d'homogeneïtzació social. ${ }^{8}$ Aquest servei durava dos anys, en els quals s'inculcava, entre altres qüestions, «una ideología de defensa fanática de los principios del 18 de julio», ${ }^{9}$ com també valors «de autoridad, de orden, disciplina ciudadana, solidaridad, apoliticismo», ${ }^{10}$ a més del nacionalcatolicisme o l'òptica de la croada salvadora. Era, per tant, un espai d'adoctrinament sociopolític i ideològic més que tan sols militarista.

Des de la Guerra Civil, a més, l'exèrcit fou encimbellat com a institució salvadora i protectora de la pàtria i, per tant, del franquisme, una imatge que va perdurar durant tota la dictadura. Acabada la guerra, l'exèrcit es va convertir en l'instrument més contundent de defensa del règim -en això consistia la seva inequívoca funció política- i, per a molts sectors del franquisme, també fou el major garant de la seva seguretat a causa de la «solidez de las virtudes ideales que constituyen el núcleo espiritual de su organización. Virtudes de honor, de lealtad, de valor y disciplina, que si para toda comunidad de seres humanos son una medida de perfección ideal y extraordinaria, en el Ejército representan condiciones de su vida cotidiana, meollo elemental de su modo de ser, médula auténtica de todo su sistema». ${ }^{11}$ Per tant, l'exèrcit durant el franquisme va tenir una inequívoca funció política: la defensa del règim. Això va ser reforçat per la Ley Orgánica del Estado, de 10 de gener de 1967, que encomanava específicament a les forces armades la defensa de l'ordre institucional.

8 J. A. Olmeda Gómez, Las Fuerzas Armadas en el Estado Franquista (Madrid: El Arquero, 1988).

9 J. Busquets I J. C. LosADA, Ruido de sables: Las conspiraciones militares en la España del siglo XX (Barcelona: Crítica, 2003), 71.

10 Aguilar Olivencia, El ejército español..., 42.

11 Ibídem, 193. 


\section{Els primers objectors de consciència: els testimonis de Jehovà}

Malgrat el context del tot desfavorable, des del final de la dècada dels anys cinquanta van començar a aparèixer els primers objectors de consciència. Els casos inicials i documentats d'objectors van ser els dels testimonis de Jehovà, que des que van arribar a Espanya a la darreria dels anys quaranta van assumir com a valor fonamental la resistència al servei armat. Però aquesta negativa responia a motius estrictament religiosos, lluny de qualsevol motivació pacifista. ${ }^{12}$ Moltes obres en què s'explica l'exemple dels testimonis de Jehovà exposen que fins al 1958 - amb el cas de Jesús Martín Nohales i l'any següent amb Alberto Contijoch Berenguer- $-s^{\prime}$ havia trobat algun tipus de solució ad hoc per als testimonis objectors. Generalment, després de diversos tractes degradants perquè abandonessin les seves actituds, se'ls oferia un servei sense armes que solien acceptar, ${ }^{13}$ la qual cosa ja no es produí arran d'aquests casos. Cap dels autors que han escrit sobre Nohales i Contijoch esmenta com la seva situació va coincidir en temps amb la guerra colonial d'Ifni. ${ }^{14}$ Potser fou

12 Els testimonis de Jehovà exposaven que no eren pacifistes —en tot cas, neutrals - i es consideraven ciutadans del regne de Déu i no del dels homes. Obeeixen les lleis de l'Estat per pura imposició, però plantegen la seva negativa quan aquestes els fan desatendre «el ministeri directe (anar de casa a casa, dirigir estudis bíblics, etc.)». A més, consideren que un cop arribat l'Armagedón que pronostica la Bíblia, seran cridats per Déu a lluitar contra les forces del mal, per la qual cosa acaba de quedar clar el seu no-pacifisme com a causa. En el llibre de Jesús Jiménez s'exposa una anàlisi extensa sobre les motivacions dels testimonis de Jehovà. Vegeu J. JimÉNEZ, La objeción de conciencia en España (Madrid: Cuadernos para el Diálogo, 1973), 47 i 125.

13 X. Rius Sant, Servei militar i objecció de consciència (Barcelona: Barcanova, 1993), 133-134.

14 Aquests autors generalment han escrit des de diverses disciplines acadèmiques o van formar part dels grups d'objecció els anys setanta i vuitanta o de la xarxa de suport dels grups. Alguns d'aquests autors i les seves obres serien: J. CAMARASA CAR RILLO, Servicio military objeción de conciencia (Madrid: Marcial Pons, 1993); G. CÁmAra Villar, La Objeción de Conciencia al servicio militar. Las dimensiones constitucionales del problema (Madrid: Cívitas, 1991), 105; JimÉnEZ, La objeción de...; A. Millán Garrido, La objeción de conciencia (Madrid: Tecnos, 1990); A. Millán Gar Rido, J. L. RoDRÍGUEZ-VILlaSANTE i E. CALDERón, Los delitos contra la prestación del servicio militar (Barcelona: J. M. Bosch, 1995); J. Oliver Araujo, La objeción de conciencia al servicio militar (Madrid: Universitat de les Illes Balears / Cívitas, 1993); X. Rius SANT, Servei militar i objecció de consciència (Barcelona: Barcanova, 1993), 133-134; V. SAmpedro Blanco, Movimientos sociales: debates sin mordaza. Desobediencia civil y servicio militar (1970-1996) (Madrid: Centro de Estudios Constitucionales, 1997), i R. SORIANO, «La objeción de conciencia: significado, fundamentos jurídicos y positivación en el ordenamiento jurídico español», Revista de Estudios Políticos 58 (1987): 61-110. 
pura coincidència, però tampoc no és desgavellat pensar que els militars no estaven disposats a tolerar cap tipus de resistència al servei militar durant un conflicte colonial -i més encara quan a França, en aquelles mateixes dates, el conflicte colonial d'Algèria va suposar una enorme efervescència de la resistència a l'allistament que va forçar el Govern a reduir les penes per negar-se a realitzar el servei militar.

La legislació amb la qual es van trobar els objectors al servei militar va ser fortament punitiva, ja que eren jutjats per la jurisdicció castrense pel delicte de «desobediència» a les ordres d'un superior previst en l'article 328 del Codi de Justícia Militar, en la modalitat d'ordres no relatives al servei d'armes. ${ }^{15}$ D'aquesta manera l'objector era condemnat a penes entre sis mesos i un dia, i sis anys. Però això no quedava aquí, perquè la condemna no eximia del servei militar; per tant, una vegada acabada, podia tornar a ser cridat a files. I tornar-s'hi a negar implicava ser jutjat novament pel mateix delicte i ser enviat a la presó. Aquesta situació podia reproduir-se fins que la persona complís trenta-vuit anys, edat a partir de la qual es passava a gaudir d'una situació de llicència absoluta, ${ }^{16}$ encara que, normalment, després de complir una quantitat variable d'anys a la presó, se'ls concedia un indult. Alberto Contijoch, per exemple, fou condemnat a tres anys i un dia de presó pel Consell de Guerra celebrat a Palma el 29 de juliol de 1959. A la mateixa ciutat, el 1961 se'l va condemnar de nou a quatre anys i un dia. I encara va sofrir una tercera condemna de sis anys, per desobediència, el 9 de juny de 1965. Després d'haver-li reduït la pena i d'haver-lo traslladat a Al-Aaiun — Sàhara Occidental—, va patir una quarta condemna de sis anys i un dia. L'abril del 1970 es beneficià d'un indult: havien passat, en total, onze anys a la presó. ${ }^{17}$

Malgrat les perspectives d'unes penes de presó tan elevades, el nombre d'objectors va començar a créixer, de manera que durant els anys sei-

15 Larticle 328 del Código de Justicia Militar, de 17 de juliol de 1945, deia el següent: «fuera de los casos comprendidos en el artículo anterior, el militar que desobedezca las órdenes de sus superiores relativas al servicio de armas, marinero o aeronáutico, incurrirá en la pena de seis años de prisión militar a veinte de reclusión militar. No tratándose de órdenes relativas al servicio de armas, marinero o aeronáutico, incurrirá en la pena de seis meses y un día a seis años de prisión militar».

16 V. Sampedro Blanco, Movimientos sociales: debates sin mordaza. Desobediencia civil y servicio militar (1970-1996) (Madrid: Centro de Estudios Constitucionales, 1997).

17 Cámara Villar, La Objeción de..., 105. 
xanta va augmentar el nombre de persones que, després de declarar-se testimonis de Jehovà ${ }^{18}$ es negaven a prestar el servei militar. ${ }^{19}$ La reacció des de la institució militar va ser sempre la repressió i el càstig: pallisses, tractes vexatoris i condemnes de presó. ${ }^{20} \mathrm{El}$ règim va dur a terme una forta repressió amb càstigs exemplars, amb l'objectiu d'escarmentar i d'evitar que es reproduïssin actituds similars. Mentrestant, a fi d'evitar aquestes "condemnes en cadena», la defensa dels objectors va provar de vegades que se'ls apliqués el delicte continuat de desobediència, denegat pel Consejo Supremo de Justicia Militar. ${ }^{21}$ En altres casos es va allegar l'atenuant d'obrar per motius morals de notòria importància i, des del 1967, es va apellar també a la Ley de Libertad Religiosa però amb prou feines es va aconseguir reduir les penes. La consideració envers els objectors seguia essent fortament repressiva. La situació tan deplorable de les «condemnes en cadena» va atreure l'interès de l'opinió pública internacional i de les institucions polítiques europees (com ara el Consell d'Europa), que van pressionar el règim perquè modifiqués el tracte jurídic cap als objectors. També en el mateix règim hi va haver qui considerava massa dura aquesta situació. El 1966, el catedràtic de Dret Internacional Luis García Arias va publicar l'article «Servicio militar y objeción de conciencia», en què advocava per «humanitzar» la legislació i evitar les «condemnes en cadena». Hi assenyalava com a solució la introducció d'una nova norma que tipifiqués el delicte de negar-se a prestar el servei militar amb la sanció corresponent, de manera que, després de complir la condemna imposada, el deute de l'individu amb la societat quedés cancellat.

18 També hi hagué alguns casos d'adventistes del Setè Dia. Com explica Jesús Jiménez, el problema dels adventistes era, d'una banda, que no podien exercir ocupació directa de les armes, però sí qualsevol altra funció militar. De l'altra, consideraven sagrat el dissabte com a dia de descans i, per tant, no obeïen ordres aquell dia. Sobretot aquest últim motiu va provocar l'empresonament de gairebé una vintena d'adventistes fins a l'any 1973. JimÉNEZ, La objección de..., 43-46.

19 En el mateix llibre de Jesús Jiménez s'exposen els casos d'objectors empresonats fins a 1973. Hi havia 268 persones, de les quals 264 eren reconegudes com a testimonis de Jehovà. Algunes d'elles eren a la presó des del 1962, i 72 feia més de cinc anys que hi eren.

20 Oliver Araujo, La objeción de...

21 Revista Española de Derecho Militar 12 (set. 1961): 301. 
La qüestió dels objectors va significar la manifestació d'una dissidència religiosa que comprometia el franquisme i la seva suposada llibertat religiosa, reconeguda en la Ley de Libertad Religiosa aprovada l'any 1967. No obstant això, aquesta norma tenia una funció estrictament política a escala internacional, pensada per transmetre «el mensaje de que el régimen estaba flexibilizando sus postulados, al menos en un terreno, el religioso [...]».22 Aquesta llei, per tant, només pretenia promoure una imatge aperturista del règim, mentre que el seu veritable fons era més que qüestionable. Els objectors de consciència empresonats revelaven com, de facto, la religiositat tan sols es podia professar com marcaven els cànons del règim. Tot el que en sortís o els contradigués era tractat com a dissidència subversiva, encara que es fes de dins mateix del cristianisme —si més no, des de l'imaginari franquista.

La mala imatge internacional que oferien gairebé dos-cents cristians empresonats per motius de credo va fer que el Govern presentés dos projectes de llei a les Corts franquistes per regular legislativament la qüestió de l'objecció de consciència. El primer fou el 1970, i el segon, un any després. Tots dos textos eren bastant restrictius i penalitzaven l'objector amb un servei substitutori sota tutela militar de tres anys. Òbviament no es tractava tota la complexitat de l'assumpte ni s'hi aprofundia, i, per tant, no es reconeixia el dret a l'objecció com a tal. ${ }^{23}$ Tots dos projectes es van discutir en la Comissió de Defensa Nacional de les Corts i tots dos van ser rebutjats. Com explica Cámara Villar sobre el projecte del 1970, malgrat la tebiesa del text, el van atacar frontalment: «lo combatieron como si con él se tratara de perpetrar un ataque frontal a las esencias ideológicas del sistema político y social. Abundaron las intervenciones que mostraban perplejidad por la actitud de los objetores, a veces calificados de psicópatas y traidores, cuando el servicio militar se revelaba a sus conciencias - y así se argumentaba - como un honor irrenunciable». ${ }^{24} \mathrm{La}$ mateixa sort va tenir el projecte del $1971^{25}$ en el debat a la cambra legislativa: es va arribar a qualificar l'objecció de consciència d' «actitud subver-

22 Molinero \& Ysàs, La anatomía del..., 94.

23 CÁmara Villar, La Objeción de...

24 Ibídem, 112-123.

25 JiméNEZ, La objeción de..., 130-135.

FRANQUISME \& TRANSICIÓ 4 (2016) ISSN 2014-511X PUNCTUM, UNIVERSITAT OBERTA DE CATALUNYA \& FUNDACIÓ CARLES PII SUNYER 
siva» i de «maniobra soviética». ${ }^{26}$ El procurador en cortes Blas Piñar López va definir la incompatibilitat dels fonaments de l'objecció de consciència al servei militar amb els valors intrínsecs del règim.

Va ser el primer cop, tant el 1970 com el 1971, que dos projectes presentats pel Govern eren rebutjats en les Corts franquistes, una circumstància que es produïa per primera vegada en la dictadura. ${ }^{27}$ Alguns autors esmentats interpreten l'oposició de les Corts orgàniques franquistes com el factor determinant que va impedir una solució palliativa a l'objecció de consciència durant el franquisme. ${ }^{28}$ No obstant això, és difícil mantenir que l'oposició de les Corts frustrés la voluntat del Govern de reconèixer, amb limitacions, l'objecció de consciència. No cal perdre de vista la naturalesa del Nuevo Estado: si Franco o el Govern haguessin volgut que el projecte tirés endavant, s'hauria executat sense problemes. Les Corts, creades el 1942, donaven simplement una imatge liberal a l'exterior i servien per diferenciar el règim dels feixismes europeus, ja que el Govern podia pressionar els procuradores en cortes, que devien el seu lloc a la voluntat governamental, o simplement actuar per decret sense comptar-hi. Resulta, doncs, poc versemblant que, per un tema d'importància menor - si es compara amb d'altres d'aquells anys-, les Corts contrariessin el Govern, i més tenint en compte que no gaudien del criteri de representativitat i que els seus membres no disposaven del dret de reunió fora de la cambra, la qual cosa els impedia tractar dels temes a debatre o preparar iniciatives o fronts comuns. El pretès «debat» parlamentari sembla respondre més aviat a una altra operació d'imatge de cara a l'exterior, que cercava aparentar que el parlament «sobirà» era el que negava el reconeixement de l'objecció de consciència. ${ }^{29}$

La voluntat de millorar la imatge exterior sobre aquest tema va ser, segons Oliver Araujo, el motiu principal que va fer considerar la qüestió

26 Diarios de las Sesiones de Comisiones 2, 6 (7 jul. 1971).

27 SAmpedro Blanco, Movimientos sociales: debates..

28 M. Gascón Abellan i L. Prieto Sanchís, «Los derechos fundamentales, la objeción de conciencia y el Tribunal Constitucional», Anuario de Derechos Humanos 5 (1988-1999): 97-120. També SORIANO, «La objeción...», 88.

29 Sobre la funció de les Corts franquistes, vegeu J. M. Thomàs AndreU, «La configuración del franquismo. El partido y las instituciones», Ayer 33 (1999): 41-55. 
dels objectors. ${ }^{30}$ Explica que Amnistia Internacional i el Consell d'Europa van pressionar el règim de Franco sobre aquest tema..$^{31} \mathrm{La}$ "proposición de Resolución relativa a la situación de los objetores de conciencia en España», presentada pel Consell d'Europa a Estrasburg el 22 de gener de 1971, lamentava «la severidad extraordinaria con la cual el derecho español amenaza a los elementos de su juventud que reclaman la objeción de conciencia» i recordava la recomanació 478 i la resolució 337, de 26 de gener de 1967, de l'Assemblea Consultiva del Consell d'Europa, sobre el dret de l'objecció de consciència; es desitjava que «el Gobierno español tome las medidas propias para establecer un estatuto de los objetores de conciencia previendo un servicio civil sustitutivo».32 Per a un tardofranquisme ansiós d'acceptació internacional, la qüestió no podia caure en l'oblit per secundària o per molt allunyada que semblés de l'agenda política interior. Com veurem amb més profunditat després, la pressió internacional va desenvolupar un paper fonamental en el tema de l'objecció de consciència.

Segons Cámara Villar, el text del 1971 buscava racionalitzar els límits del càstig als objectors, que es consideraven d'alguna manera «traïdors» envers la pàtria. ${ }^{33}$ El Govern va optar per tipificar expressament el delicte de negar-se a complir el servei militar i la sanció corresponent. Això es va discutir, i després es va materialitzar en la Llei 29/1973, de 19 de desembre de 1973, que va introduir l'article 383 bis en el Código de Justicia Militar. ${ }^{34} \mathrm{Amb}$ aquest delicte d'objecció de consciència incloïa entre tres

30 Oliver Araujo, La objeción de...

31 Podien pressionar el règim sobre l'entrada d'Espanya en la CEE, una qüestió especialment sensible perquè el 1962 n'havia formalitzat la sollicitud d'adhesió per interessos econòmics i de reconeixement internacional. No obstant això, topava amb una dificultat: la incompatibilitat legislativa amb la resta dels països de la comunitat, ja que la dictadura franquista no era un règim democràtic, encara que pretengués semblar-ho. Per tant, la qüestió de l'objecció de consciència, considerada en altres països europeus, podia utilitzar-se com a forma de pressió i d'evidència — com en molts altres casos-d'aquesta manca de compatibilitat democràtica real. Sobre els intents d'integració de la dictadura en la CEE, vegeu C. T. PoweLL, «España en Europa: de 1945 a nuestros días», Ayer 49 (2003): 81-119. També C. Molinero i P. Ysàs, Història política 1939-200o (Madrid: Istmo, 2001), 154-162.

32 Rius SAnt, Servei Militar..., 134-135.

33 Cámara Villar, La Objeción de...

34 Concretament, el capítol V bis: «Negativa a la prestación del servicio militar», dins del títol XII, «Delitos contra los fines y medios de acción del Ejército» del Código de Justicia Militar. En OLIver Araujo, La objeción de..., 107-108. 
anys i un dia a vuit anys de presó en temps de pau, i una pena de reclusió major si es produïa en temps o estat de guerra. S'acabaven les condemnes en cadena, ja que el compliment de la sanció suposava la cancellació del deute de l'objector amb la societat; «excepto en caso de movilización por causa de guerra o declaración de estado de guerra». ${ }^{35} \mathrm{~A}$ més del càstig de presó, la persona era condemnada a àmplies inhabilitacions públiques, de manera que no podia exercir el que la legislació considerava «drets polítics», ostentar càrrecs i funcions públiques, ni establir relacions laborals i contractuals de cap ordre amb entitats públiques; també quedava incapacitada per a la docència pública i privada, i per obtenir —lògicament, perquè es negava a fer el servei d'armes - el permís de tinença i ús d'armes. La rehabilitació tan sols era possible mitjançant el compliment efectiu dels deures militars.

Per a Sampedro Blanco, la regulació estava pensada perquè s'apliqués una condemna mínima als testimonis i una condemna màxima a aquells de religió catòlica, que van començar a aparèixer el 1971 i als quals ens referirem a continuació. Aquests nous objectors van ser joves molt polititzats. ${ }^{36}$

La Llei 29/1973, per tant, no era més que una reforma del Código de Justicia Militar. El president del Govern Carrero Blanco, veia en les relacions exteriors un problema candent que calia esquivar d'alguna manera. El 1973, el Vaticà va exigir una revisió total del concordat i es va negociar amb el Mercat Comú Europeu un nou protocol addicional. Era, doncs, un context en el qual les pressions exteriors podien anar en contra dels interessos de la dictadura si no hi havia gestos en la direcció adequada. Potser per això, aquell mateix any, es van revisar les condemnes de presó, òbviament sense reconèixer el dret d'objecció de consciència, sinó, simplement, atenuant-ne el grau de repressió. Així, sense qüestionar el que s'entenia que formava part de les essències del règim, se'n podia millorar la imatge a l'estranger. ${ }^{37}$ Per tant, sembla més lògic pensar que el Govern va acabar aprovant allò que simplement volia aprovar. De passada, s'o-

35 Ibídem.

36 Sampedro Blanco, Movimientos sociales: debates..., 128.

37 Ibídem.

FRANQUISME \& TRANSICIÓ 4 (2016) ISSN 2014-511X PUNCTUM, UNIVERSITAT OBERTA DE CATALUNYA \& FUNDACIÓ CARLES PI I SUNYER 
feria a l'opinió internacional una imatge de control parlamentari purament fictícia però funcional per a les credencials democràtiques que la dictadura pretenia que li fossin reconegudes, contra tota lògica. ${ }^{38}$

En definitiva, l'atenció que va començar a donar el Govern a l'objecció de consciència el 1970 significa que ja s'havia convertit en un assumpte a considerar per al règim. Com he assenyalat, la qüestió dels objectors va implicar una dissidència religiosa que va transcendir a la política i que va adquirir una dimensió més gran quan van aparèixer els primers casos d'objectors catòlics el 1971, arran dels quals l'objecció es va carregar de motivacions polítiques, de manera més o menys explícita.

\section{Els «nous» objectors de consciència}

En la dècada dels anys setanta van aflorar joves que, sense ser testimonis de Jehovà, es van negar a fer el servei militar. Aquests primers joves van portar a cap l'objecció inspirats, sobretot, per la doctrina de la noviolència. Tant l'objecció de consciència d'aquests nois com el seu coneixement sobre la no-violència van estar determinats pels objectors i no violents francesos. En aquesta influència va tenir-hi una funció important la relació amb grups d'objectors i no violents, dins dels quals va destacar la Communauté de l'Arche de Lanza de Vasto. Els contactes amb aquesta comunitat van començar al final de la dècada dels anys cinquanta, a través de determinats cercles catòlics propers a revistes com El Ciervo. D’aquesta manera, el 1958 la Communauté va ser visitada pel sacerdot Josep Dalmau, i el 1959, per Alfons Carles Comín. ${ }^{39}$ Tots dos van promoure que Lanza del Vasto vingués a Barcelona el 1959, on va pronunciar conferències sobre la no-violència i l'experiència de la Communauté. En aquest viatge va contactar amb membres d'El Ciervo, com ara Jordi Maluquer, el

38 El franquisme, en especial des de la segona meitat de la dècada dels cinquanta, va mostrar una certa obsessió per ser reconegut internacionalment com un règim amb un sistema democràtic equivalent al que hi havia en les democràcies europees. Aconseguir això era fonamental per al reconeixement internacional, com també per a l'adhesió a estructures com la CEE. Sobre aquesta temàtica, vegeu Molinero \& Ysàs, Anatomia del franquismo..., 42-43 i 62-63.

39 Comín va publicar un article sobre Lanza del Vasto i la Communauté de l'Arche en la revista El Ciervo (abril del 1959). 
qual, al costat d'altres participants de la conferència, van fundar Amics de l'Arca. La majoria dels integrants eren catòlics. Sense que el grup estigués integrat en cap estructura de l'Església, la seva activitat girava al voltant de la difusió de la no-violencia i el treball grupal basat en l'espiritualitat. ${ }^{40}$

L'agost del 1967, Amics de l'Arca va organitzar a Castellterçol el primer campament, al qual van assistir el mateix Lanza del Vasto i 96 persones de tot Espanya.$^{41}$ Fou la primera trobada de quatre més de consecutives els anys immediatament posteriors, en què, a més de parlar de la noviolència, «se realizaban plegarias, cantos, talleres de artesanía y ejercicios de yoga.$^{42}$ Aquests campaments es van desenvolupar sense cap permís oficial: els organitzadors van aconseguir que les autoritats locals els consideressin inofensius tot alludint al sentit cristià que tenien. ${ }^{43}$ L'afluència va anar creixent, fins a reunir-hi aproximadament 300 persones. ${ }^{44}$

Aquestes trobades van ser molt importants per al desenvolupament de la xarxa de suports dels objectors de la dècada dels setanta. Per exemple, Lluís Fenollosa explica que en el campament del 1967, «10 o 12» persones van decidir formar un grup de «no-violència activa». En aquest grup hi havia joves de València, Euskadi, Madrid i Barcelona, els quals van analitzar les diferents propostes d'acció sobre qüestions «que reflecteixin la màxima expressió de la violència». Una d'aquestes era el servei militar, de manera que van plantejar dur-ne a terme l'objecció de consciència. Aquests joves consideraven les connotacions polítiques de l'acció perquè eren conscients, d'una banda, del context de la dictadura i, de l'altra, que la qüestió afectava un dels pilars del règim: l'exèrcit. Dos membres del grup, els germans Xabier i Iñaki Urdanibia, de Sant Sebas-

40 X. GARÍ de BARBARÀ, Els primers collectius i organitzacions per la pau i la no-violència sorgits a Catalunya: dècades dels anys 50 i 60 (Bellaterra: Universitat Autònoma de Barcelona, 2002).

41 «Ressenya de la Marxa Internacional pel Dret a l'objecció de consciència», compilació de successos realitzada per Lluís Fenollosa el 1972 i facilitada per l'autor.

42 E. Prat i Carvajal, Moviéndose por la paz. De Pax Christi a las movilizaciones contra la guerra (Barcelona: Hacer, 2003), 29.

43 Ibídem, 29.

44 P. Ortega, La societat noviolenta. Converses amb Pepe Beunza (Barcelona: Icària / Institut Català Internacional per la Pau, 2012), 39. 
tià, es van plantejar seriosament efectuar l'objecció de consciència, encara que finalment van desistir. ${ }^{45}$

En el campament del 1968, de nou a Castellterçol, José Luis Beunza (conegut com a Pepe Beunza) va exposar la idea de fer-se objector i va aconseguir suport; sobretot pel que fa a la formació d'un grup denominat Equip OC. Entre els integrants hi havia Fenollosa, Marta Casas, Maluquer i Gonzalo Arias. Arias, que fou un dels promotors principals de la no-violència a Espanya, també hi participà i va ser una de les persones que més suport donà a la campanya de Beunza fins a crear entre ells una collaboració molt estreta.

L'Equip OC, que més endavant s'acabaria integrant en Pax Christi, era conscient del difícil compromís personal que suposava assumir l'objecció de consciència, derivat de la forta càrrega punitiva que aquells anys s'aplicava als que es negaven a fer el servei militar, de manera que el grup va centrar-se a sensibilitzar l'opinió pública. Els seus membres van maldar per fer campanyes de difusió i buscar el compromís de persones i organitzacions notòries, a més d'enviar cartes al Govern per reclamar l'aprovació d'un estatut per a l'objecció de consciència. ${ }^{46}$

L'objecció de consciència que va començar Pepe Beunza va estar afavorida, d'una banda, pel context d'extensa mobilització antifranquista de l'última etapa de la dictadura, en el qual la lluita per l'objecció de consciència va formar part del conjunt de demandes democràtiques exigides per l'antifranquisme; i de l'altra, pel suport de determinats espais catòlics des dels quals es podia desenvolupar i potenciar aquesta qüestió.

L'objecció de consciència es va gestar i desenvolupar durant el tardofranquisme, en un context d'elevada i estesa dissidència contra el règim. En aquest clima d'oposició va tenir un paper clau l'expansió d'uns moviments socials de creixent fortalesa, de considerable presència pública i d'inequívoc caràcter polític. Eren grups que anaven més enllà de determinats centres urbans i les motivacions polítiques dels quals - no eren mai exclusivament econòmiques - superaven moltes vegades les pers-

45 «Ressenya de la Marxa Internacional pel Dret a l'objecció de consciència», compilació de successos realitzada per Lluís Fenollosa el 1972 i facilitada per l'autor.

46 Ibídem. 
pectives democràtiques habituals, per esdevenir socialment revolucionàries. ${ }^{47}$ En aquesta última etapa de la dictadura hi havia una conflictivitat social diversa i creixent, impulsada per l'activisme antifranquista a través de CCOO i de grups sindicals i polítics, del moviment veïnal, del moviment estudiantil, que rebia suport de collectius professionals, intellectuals, artistes i sectors significatius del món del clergat catòlic. Tot aquests agents, des dels seus fronts de lluita — que eren diversos però estaven relacionats - van configurar un activisme i van organitzar una conflictivitat complexa, diversa, extensa i intensa, la qual va anar erosionant la dictadura i va gestar les condicions polítiques que determinaren el procés de transició cap a la democràcia, ${ }^{4}{ }^{8}$ a més d'incentivar l'expansió d'una cultura democràtica, el dissentiment contra la dictadura i el compromís amb l'oposició. Es va produir, doncs, una multiformitat de la conflictivitat antifranquista que no era protagonitzada per la majoria de la societat ni tampoc per minories, sinó per la «immensa minoria» dels ciutadans. ${ }^{49}$

La mobilització sociopolítica antifranquista va ser el factor bàsic per a la crisi i liquidació de la dictadura. No obstant això, la crítica i la mobilització mai no van aconseguir ser un perill efectiu d'ensulsiada o collapse absolut i immediat, sobretot a causa de l'aparell coercitiu i de les pràctiques repressives. Per al franquisme, però, el fet que existissin, s'expandissin i reproduïssin comportava una amenaça real i un fracàs, perquè el règim, que es vanava de ser un model d'ordre, no el podia garantir fins al punt d'haver de recórrer al «estado de excepción».

47 J. A. PÉREz, Los años del acero. La transformación del mundo laboral en el área del Gran Bilbao (1958-1977). Trabajadores, convenios y conflictos (Madrid: Biblioteca Nueva, 2001); X. Domènech, Quan el carrer va deixar de ser seu. Moviment obrer, societat civil i canvi polític. Sabadell (1966-1976) (Barcelona: Publicacions de l'Abadia de Montserrat, 200o); Clase obrera, antifranquismo y cambio político (Madrid: Los Libros de la Catarata, 2008); Cambio político y movimiento obrero bajo el franquismo. Lucha de clases, dictadura y democracia (1939-1977) (Barcelona: Icària, 2012); C. CARNICERo, La ciudad donde nunca pasa nada. Vitoria, 3 de marzo de 1976 (Gasteiz: Eusko Jaurlaritza-Gobierno Vasco, 2007), i S. RODRÍGUEZ TEJADA, Zonas de libertad. Dictadura franquista y movimiento estudiantil en la Universidad de Valencia (València: Universitat de València, 2009).

48 I. SAZ CAmpos, «Mucho más que crisis políticas: el agotamiento de dos proyectos», Ayer 68 (2007): 137-163.

49 Molinero \& Ysàs, Productores disciplinados y...; P. Ysàs, Disidencia y subversión: la lucha del régimen franquista por su supervivencia. 1960-1975 (Barcelona: Crítica, 2004). 
A més de l'impuls considerable que l'antifranquisme va rebre des del moviment obrer i l'estudiantil, als barris va començar a brollar un moviment veïnal potent i combatiu que evidenciava l'ampli descontentament originat per les condicions de vida per a la major part de la població. Unes condicions que, malgrat el creixement econòmic dels últims anys, no s'havien manifestat prou per a una quantitat substancial de la societat. La política desarrollista dels anys seixanta va generar, en els principals nuclis urbans, una sèrie de suburbis amb mancances significatives, arran de les quals es va anar coent un discurs crític contra el règim que va desembocar en moviment social. El moviment veïnal va estar íntimament relacionat i influit pel moviment obrer, sobretot a l'origen..$^{\circ}$

Cal advertir, també, de fins a quin punt l'oposició antifranquista va influir sobre el desenvolupament més pausat d'altres lluites «sectorials», com ara el reconeixement del dret a l'objecció de consciència. La unió entorn de l'objectiu comú de posar fi a la dictadura va suposar una relació de «discussió, polèmica i/o diàleg» amb moviments socials com l'obrer, la qual cosa va incidir en la feblesa o fortalesa d'altres grups socials i, també, en els propis ritmes. ${ }^{51}$

En aquest context d'activisme social i de repressió, la resistència al servei militar va començar a fer-se real, encara que d'una manera molt aïllada i minoritària, per l'acció de diversos joves que es van negar a realitzar el servei d'armes i que gaudien de suport nacional i internacional (en parlarem més endavant). Com veurem a continuació, en la majoria dels casos la inspiració era religiosa - procedia de cercles cristians diversos, no només catòlics - i, a més, també estava molt vinculada —encara que no sempre- a la doctrina de la no-violència, d’orígens religiosos i laics.

50 Sobre el moviment veïnal, vegeu: X. Domènech, «Orígenes. En la protohistoria del movimiento vecinal bajo el franquismo", Historia del Presente 16 (2010): 27-41; C. Molinero i P. Ysàs, Construint la ciutat democràtica. El moviment veïnal durant el tardofranquisme i la transició (Barcelona: Icària, 2010); R. MARTínEZ i MUNTADA, «Movimiento vecinal, antifranquismo y anticapitalismo", Historia, Trabajo y Sociedad 2 (2011): 63-9o i I. BordETAs, «Nosotros somos los que hemos hecho esta ciudad. Autoorganización y movilización vecinal durante el tardofranquismo y el proceso de cambio político» (Tesi doctoral, Universitat Autònoma de Barcelona, 2012).

51 Sobre aquesta relació de «discusión, polémica y/o diálogo» entre moviments socials, vegeu: $\mathrm{F}$. FERnÁNDEZ BUEY, «Els moviments socials alternatius; un balanç», dins E. Prat i CARvaJAL, Els moviments socials a la Catalunya contemporània (Publicacions i Edicions de la Universitat de Barcelona: Barcelona, 2004), 21-49. 
En efecte, l'objecció de consciència va trobar en determinats àmbits del món catòlic espais per desenvolupar-se i potenciar-se (sobretot en el cas de grups afins als postulats del concili II del Vaticà). L'assemblea confirmava el canvi que es va produir en el món catòlic. En serien una bona mostra les encícliques Mater et Magistra, del 1961, i Pacem in Terris, del 1963, que van provocar nombroses convulsions en el catolicisme internacional, inclòs l'espanyol, atès que el marc de llibertats i drets humans que definien no encaixava amb el que es vivia al sud dels Pirineus. El concili va comportar l'obertura definitiva de les tensions del nou món catòlic i el règim franquista, en especial a partir del 1967.52 Malgrat les resistències dels bisbes espanyols durant la dècada dels anys setanta, la renovació fou cada vegada més notòria. L’Església catòlica començava a esquerdar el que fins llavors havia estat l'adhesió incondicional al règim, de manera que el món catòlic va deixar de ser a poc a poc un espai de confiança i complicitat totals per a la dictadura. ${ }^{53}$

Com va passar en el cas dels obrers, veïns i estudiants, els objectors van trobar entre aquests sectors crítics de l'Església un espai per explicar i difondre les seves causes. ${ }^{54}$ Aquest suport es va traduir en una collaboració a l'hora d'accedir a cercles del règim per reclamar un estatut de reconeixement legal de l'objecció de consciència. El món catòlic, que havia canviat d'actitud pel que fa a l'objecció de consciència durant el concili, va entendre la resistència al servei militar com un dret personal més que havia de ser reconegut a Espanya i en la resta dels països catòlics, per la qual cosa va adoptar una actitud comprensiva i receptiva cap als objectors. En aquest sentit es van manifestar els sínodes de bisbes del 1971 i del $1973^{55} \mathrm{O}$, prèviament, la Comissió Episcopal de Missions, que el 1968 havia dema-

52 H. Raguer, Réquiem por la cristiandad: el Concilio Vaticano II y su impacto en España (Barcelona: Península, 2006).

53 F. BlázQuez, La traición de los clérigos en la España de Franco. Crónica de una intolerancia (1936-1975) (Madrid: Trotta, 1991); J. DomínguEZ, Organizaciones obreras cristianas en la oposición al franquismo, 1951-1975 (Bilbao: Mensajeros, 1985).

54 Tal com explica Vicenç Fisas, l'Equip OC es reunia en un pis al carrer de Mallorca de Barcelona, llogat en nom del bisbat, i des d'allà organitzava la seva activitat. Entrevista a Vicenç Fisas Armengol (24 abr. 2014).

55 «a justicia en el mundo. Nuevas responsabilidades de la Iglesia en el campo de la justicia», Sínode Mundial de Bisbes, Roma, 1971. Consultat a la pàgina web de la Conferencia Española de Religiosos: http://www.confer.es/725/activos/texto/wcnfr_pdf_2566-U1bgv1kNzDHk7cr2.pdf. 
nat que la nova Ley General del Servicio Militar incorporés la possibilitat de fer un servei de cooperació apostòlica a l'estranger. En aquesta comissió, alguns bisbes, com els d'Osca i Sant Sebastià —Javier Osés i José María Setién, respectivament-, van mostrar una actitud favorable cap als objectors, que es va estendre a l'Assemblea Episcopal Espanyola el $1973 .{ }^{.6}$ De fet, aquest òrgan va emetre una nota en la qual recordava les resolucions del concili i instava el Govern espanyol a actuar-hi en conseqüència. ${ }^{57}$ Prèviament, l'Assemblea Conjunta de Bisbes i Sacerdots espanyols del 1971 reconeixia que a Espanya «le queda mucho camino que recorrer en lo que se refiere al reconocimiento jurídico y a la realización de los derechos de la persona humana, tal como son expuestos en la Pacem in Terris y en el Concilio [...] [como por ejemplo en lo referido al] derecho a la objeción de conciencia por motivos éticos o religiosos»..$^{8}$

A més d'aquests posicionaments concrets durant la dècada dels seixanta i setanta, en universitats confessionals com Deusto, Comillas i l'Institut León XIII es van obrir fòrums de debat sobre la qüestió. També van començar a aparèixer en nombroses publicacions catòliques articles a favor de l'objecció de consciència. Així ho constaten alguns números de revistes, com ara Vida Nueva, Mensajero, Incunable, Mundo Social i IglesiaMundo. ${ }^{59} \mathrm{Hi}$ hagué dues publicacions que feia temps que s'havien situat clarament dins d'un pacifisme crític i que van donar un suport especial a l'objecció de consciència i als objectors: El Ciervo i Cuadernos para el Diálogo.$^{60} \mathrm{~A}$ més d'aquestes publicacions, els objectors i l'aposta per la no-violència com a via per a la resolució de conflictes van trobar el suport de dues associacions de catòlics pacifistes. Un d'aquests grups era Pax Christi, que s'havia implicat en la causa des del principi — de fet, gran

56 «Documento de la Conferencia Episcopal Española sobre la objeción de conciencia», dins M. Ortiz Heras, Culturas políticas del nacionalismo español: del franquismo a la transición (Madrid: Los libros de la Catarata, 2009), 235.

57 Oliver Araujo, La objeción de...

58 «Proposición aprobada el 15 de septiembre de 1971», Asamblea Conjunta de Obispos y Sacerdotes Españoles.

59 Vegeu: Vida Nueva 784 (maig 1971), 798 (set. 1971); Mensajero 989 (des. 1971); Incunable 262263 (ag. 971); Mundo Social 189 (juny 1971), i Iglesia-Mundo 65 (des. 1973). En aquests articles es defensava la compatibilitat de l'objecció de consciència amb la idiosincràsia de l'Evangeli i el seu llenguatge de pau i fraternitat.

6o Prat i Carvajal, Activistes de la pau..., 19 i següents. 
part de l'Equip OC s'hi va incorporar: va participar de manera activa en la campanya per Pepe Beunza quan aquest va entrar a la presó; el març de 1973, va presentar a les Corts un projecte d'estatut per als objectors de consciència, ${ }^{61} \mathrm{i}$ a partir del 1973 va publicar en set números el butlletí Pax, en què la teoria i la pràctica de «alternativa revolucionària» ocupava un lloc preeminent. ${ }^{62}$ L’altra era Justicia y Paz. El 1973, la Comisión Nacional de Justicia y Paz va elaborar un informe sobre l'objecció de consciència, en el qual reconeixia la no-violència i l'objecció de consciència com «la expresión de un deseo de crear una nueva humanidad de la que se destierren la injusticia, el hambre y la incultura, causas del odio y de la guerra». Una de les accions de Justicia y Paz per aconseguir el reconeixement de l'objecció de consciència va ser incentivar la campanya «Voluntariado para el Desarrollo». La promoció fou a càrrec de Pepe Beunza i Gonzalo Arias, que van recórrer el territori espanyol durant el 1974 per divulgar l'objecció de consciència i plantejar la possibilitat d'un servei alternatiu que revertís en les necessitats dels barris. ${ }^{63}$ La proposta va ser presentada al Govern el 5 de maig de 1975 , amb el suport de Justicia y Paz. ${ }^{64}$ Es van crear grups d'objectors i de suport, i es van recollir una mica més de 1.200 signatures de joves - una quarta part de les quals eren de dones-, disposats a fer el voluntariat. La documentació elevada al president del Govern incloïa una llista d'organitzacions socials que els acollirien. La proposta va aconseguir la mediació de procuradors a les Corts, com ara Marcelino Oreja, i de personalitats de gran rellevància pública, com ara Joaquín Ruiz-Giménez, Gabriel Cisneros, Enrique Miret Magdalena i Juan José Rodríguez Ugarte. ${ }^{65}$ No obstant això, va ser ignorada per l'executiu. El 17 de novembre de 1976, ja amb el primer govern de Suárez en plena tran-

61 «Propuesta de enmienda del art. 383 bis del Código de Justicia Militar», 2 agost 1973, i «Propuesta de Proyecto de estatuto para los objetores de conciencia, 1973, Pax Christi, documents interns», dins SAm PEDro Blanco, Movimientos sociales: debates..., 136.

62 Pavelló de la República de la Universitat de Barcelona, caixes 79.4, 1-3.

63 Entrevista d'Ana Isabel Simón Alegre a Pepe Beunza (Barcelona, 2008) per al projecte Historia oral de la transición. Testimonios de cambio (1965-1982), i P. Oliver OlMO, «Los iniciadores del movimiento de objetores de conciencia (1971-1977)», dins Manuel Ortiz Heras, Culturas políticas del nacionalismo español: del franquismo a la transición (Madrid: Los libros de la Catarata, 2009), 235.

64 J. L. Lafuente Del Campo i J. Viñas i Cirera, Los objetores. Historia de una acción (Madrid: Cares, 1977), 17-18.

65 A. Millán Garrido, La objeción de conciencia (Madrid: Cívitas, 1990). 
sició, la Comissió Nacional de Justicia y Paz va tornar a insistir-hi i va enviar a la Presidència del Govern un nou projecte d'estatut per als objectors de consciència, sense que tampoc obtingués una atenció especial. ${ }^{66}$

\section{Dissidència política i ideològica}

Com ja s'ha comentat, Pepe Beunza va ser el primer jove que es va declarar objector, sense ser testimoni de Jehovà. ${ }^{67}$ Va portar a terme la seva acció l'any 1971, i durant els anys següents, només set persones més van realitzar l'objecció de consciència, fins que el 1975 tingué lloc el primer cas d'objecció collectiva: set joves de diferents indrets del territori espanyol van engegar un servei civil al barri de Can Serra de l'Hospitalet de Llobregat (Barcelona). L'experiència de Can Serra es va reproduir l'any posterior en barris de Bilbao, Madrid, Màlaga, Reus, Tarragona i Vic, ${ }^{68}$ i, a poc a poc, es van anar creant grups d'objectors en diverses ciutats espanyoles que van donar origen al Moviment d'Objectors de Consciència (MOC) el gener del 1977. Aquest grup es convertiria en la principal organització dels objectors espanyols durant els anys següents i en l'eix vertebrador del moviment antimilitarista que es va desenvolupar plenament en les dècades dels vuitanta i noranta.

Encara durant els anys setanta, l'acció de Beunza va ser fonamental per obrir el camí i per situar la resistència al servei militar dels joves espanyols en una dinàmica similar a la de molts països europeus d'ençà de la Primera Guerra Mundial. Si una cosa especial té el seu cas és que havia madurat prèviament la seva acció i li va saber conferir un caràcter netament polític. La determinació del jove Beunza va estar fortament influenciada pel contacte previ amb les doctrines de la no-violència i de l'objecció de consciència a França. ${ }^{69} \mathrm{~A}$ més de participar en campaments

66 Lafuente Del Campo \& Viñas i Cirera, Los objetores. Historia..., 214-221.

67 L'acció de Beunza és relatada en gairebé totes les obres que expliquen el desenvolupament de l'objecció de consciència a Espanya. Centrades en l'acció de Beunza podeu llegir: P. Oliver Olmo, La utopía insumisa de Pepe Beunza. Una objeción subversiva durante el franquismo (Barcelona: Virus, 2002).

68 «La Objeción de Conciencia, un derecho», Canigó (14 ag. 1976).

69 Oliver Olmo, La utopía insumisa... 
d'Amics de l'Arca, l'estiu del 1967 va estar a la Communauté de l'Arche de Lanza de Vasto, una experiència que va marcar inequívocament la seva manera de pensar i d'actuar, i durant les campanyes de verema va tenir l'oportunitat de contactar amb diversos objectors i refractaris francesos de la guerra d'Algèria, a banda d'objectors belgues i suïssos.

$\mathrm{Al}$ costat de Beunza hi hagué casos poc premeditats d'objectors que van optar-hi per raons personals i profundes conviccions cristianes, de vegades sense conèixer-ne, si més no, el concepte. Les motivacions cristianes es basaven en interpretacions pacifistes de l'Evangeli, del Sermó de la Muntanya i, sobretot, de la vida de Jesús. Manaments com «no mataràs» i el missatge d'amor al proïsme, inclosos els enemics, van motivar aquestes accions. D’aquesta manera, el mateix any 1971 tres joves més van decidir resistir-se al servei militar. Eren, per ordre d'aparició: Jordi Agulló Guerra, Joan Guzmán Salvadó i Víctor Boix. Durant el 1972 sorgiren tres casos nous: Juan Antonio Linares i els sacerdots Francisco López de Fumada i Juan Pescador Mesonero. El 1974 s'hi sumaria Rafael Rodrigo Navarro. ${ }^{70}$

Cap altre noi va fer efectiva l'objecció fins al 1975, la qual cosa no significa que no hi hagués joves que pensessin igual, sinó que les implicacions personals van acabar frenant les intencions. Aquest va ser el cas de Manuel Luis Emilio Jerónimo Calle, de Badajoz, que l'abril del 1974 va escriure al capità general de la segona regió militar. ${ }^{71} \mathrm{I}$ el de Vicenç Fisas Armengol, que va conèixer el cas de Pepe Beunza per un pamflet de l'Equip OC. Més tard, s'incorporaria al grup i acabaria essent-ne un dels activistes més destacats per l'objecció de consciència i, poc temps després, pel desarmament i l'antimilitarisme. El mateix Fisas explica que no estava

70 Sobre l'acció d'aquests objectors, com també dels seus contextos personals, vegeu: Oliver Olmo, «Los iniciadores del...», 219-244; Comisión Nacional De Justicia y PAZ, Informe sobre la Objeción de Conciencia, 1973 (Justicia y Paz, 1973); en els casos de Jordi Agulló i Joan Guzmán hi ha entrevistes de cadascun d'ells fetes per Ana Isabel Simón Alegre (Barcelona, 18 de desembre de 2008) per al projecte Historia oral de la transición. Testimonios de cambio (1965-1982), Seminario de Fuentes Orales de la UCM-Ministerio de Cultura; per als casos d’Agulló, Guzmán, López de Ahumada, Pescador Mesonero i Rodrigo s'han consultat les caixes 26 i 78 del fons MOC, de l'Ateneu Enciclopèdic Popular (AEP) de Barcelona.

71 «Objetor de uniforme», carta de Manuel Luis Emilio Jerónimo Calle al capità general de la Segunda Región Militar, Badajoz, 16 de març de 1974, caixa 78, fons MOC, AEP, Barcelona. 
disposat a fer la mili, però que quan va ser cridat a files «tenia la possibilitat de passar uns anys a la presó o fer de pare». La situació familiar, finalment, va fer que es presentés a la crida a files. ${ }^{72}$ Són, doncs, exemples documentats d'objectors de consciència i de contraris al servei militar per motivacions ideològiques, però que per un motiu o un altre van acabar a files. No obstant això, a totes les lleves anuals hi hagué un cert percentatge de desertors, pròfugs i condemnats pel delicte de desobediència, de manera que és difícil assegurar quins d'aquests tenien motivacions polítiques, filosòfiques o religioses. La manca d'estudis sobre aquest tema fa que no es pugui conèixer la representativitat d'aquests casos.

En les motivacions dels objectors que van fer pública la resistència al servei militar hi havia una crítica política considerable, sia per la càrrega de crítica implícita en la doctrina de la no-violència, sia pel desenvolupament d'una manera d'entendre el catolicisme diferent de l'establert durant el franquisme. En aquest sentit, un dels primers objectors, Joan Guzmán, explicava com la seva manera de viure el catolicisme l'oposava al servei militar:

El hecho de aprender a manejar un fusil, para matar a otros semejantes, sólo porqué están más allá de una demarcación, llamada frontera, y porque así el hombre lo había impuesto no me parecía razonable ni humano y por otro lado no podía ni digerirlo. [...] ¡Deseo ser un buen cristiano, seguir a Cristo con todas mis fuerzas y predicar y enseñar su doctrina de Amor! [...] Aquella misma noche me presenté al oficial de guardia y le presenté sin la menor vacilación mi «objeción de conciencia» respecto a continuar el servicio a la patria con las armas. ${ }^{3}$

Un altre dels objectors d'aquells anys, Jerónimo Calle, alludia a la situació de la seva regió durant la dictadura «Badajoz [sufre] una enfermedad incurable, cuyos síntomas inequívocos son: analfabetismo, niños sin escolarizar, maestros en paro, falta de escuelas, baja renta per cápi-

72 Entrevista a Vicenç Fisas Armengol (24 abril 2014).

73 «Joan Guzmán, Un saludo comunicativo de un objetor», Cartagena, 3 de juliol de 1972, C 78, fons MOC, AEP, Barcelona. 
ta, mortalidad infantil elevada, paro obrero con sus diversas afecciones, que provocan el desempleo y la emigración por la falta de industrialización... Esta enfermedad puede ser fácilmente diagnosticada con el nombre de subdesarrollo».74 Per això considerava totalment injustificades les despeses militars, a més d'evidenciar el subdesenvolupament que patien determinats llocs de l'Espanya franquista, la qual cosa feia que el seu allegat estigués imbuït de crítica política.

Com a últim exemple, Jordi Agulló es mostrava més contundent després del seu periple per la presó. Després de tornar a ser cridat a files, va decidir no legalitzar la seva situació desobeint la llamada a filas, ja que «al fin y al cabo, todos sabemos que lo legal, en la actual España, es la institucionalización del desorden establecido que sólo busca el beneficio de los que mandan y del capitalismo». Tampoc no decideix entregar-se, ja que així seria empresonat i, per tant, «un gasto más a sumar en la carga, ya pesada, de la clase trabajadora [...] en un país donde la clase trabajadora se lo carga todo: producir los medios de consumo para todos los que están arriba; al mismo tiempo debe dar hijos suyos para crear los cuerpos represivos, para que la misma no se emancipe y se harte de producir para todos y que sólo se nos den los restos; debe también entregar sus hijos por periodo de un año y medio al Ejército, para mantener una constante fuerza de dominio que mantenga el "orden" y la "paz"».75 Tal com explicitava Agulló, el seu pensament està carregat d'ideologia socialista.

Tots aquests exemples mostren que l'objecció de consciència no era simplement una posició de consciència individual de persones pacífiques o pacifistes que s'oposava a fer servir les armes, ni tampoc que va estar relacionada del tot a maneres d'entendre la religiositat diferents de la nacionalcatòlica, sinó que en aquestes posicions es manifestaven crítiques socials i polítiques, es qüestionaven les situacions de desigualtat i la despesa militar en un món amb nombroses emergències humanes. Era, doncs, un tipus de protesta política contra el subdesenvolupament i la desigualtat social, que es patia en molts racons d'Espanya. I una actitud que podia ar-

74 «Objetor de uniforme», carta al capitán General de la Segunda Región Militar, Badajoz, 16 d'abril de 1974, caixa 78, fons MOC, AEP, Barcelona.

75 «Carta al Capitán General de la Zona del Mediterráneo» (28 juny 1974), C 78, fons MOC, AEP, Barcelona. 
ribar a ser habitual els anys seixanta i setanta, però que no havia arribat a cristallitzar en un fenomen de masses.

El desenvolupament teòric i pràctic més gran d'aquest dissentiment que condueix a l'objecció de consciència pot veure's en Pepe Beunza. Amb la seva acció denunciava i feia crítica explícita a les injustícies de l'Espanya franquista. Per a Beunza, la seva protesta era una implicació «por la patria, la libertad y la justicia en un país en el que existen sin el grado que yo considero necesario [...]. No quiero convertirme en una máquina de obedecer órdenes, que me haga renegar de mi conciencia de hombre libre y menos para servir a la oligarquía de gobernantes, banqueros y terratenientes que, con el apoyo del Ejército y la bendición de la Iglesia Oficial, mantienen estructuras de opresión que impiden el desarrollo de la justicia y la libertad, y por si esto fuera poco se acaban de unir por un pacto a todo el proceso imperialista americano». ${ }^{76} \mathrm{La}$ desigualtat social i econòmica d'Espanya era una de les qüestions més intolerables per a Beunza: «mientras nuestra sociedad esté en manos de 200 personas dueñas de la banca y los monopolios, mientras que un $1 \%$ de los propietarios posean más de la mitad de las tierras de España, mientras que, como en nuestra provincia [València], 111 fincas ocupen más de la tercera parte de la superficie total, no podemos exigir, salvo engañándolos, que hombres cuyo único haber son la miseria y los callos en las manos arriesguen su vida por defender la riqueza de los demás».77 I hi afegia: «en España hay siete millones y medio de analfabetos y un millón de niños sin escuela (datos del Informe FOESSA) y por esto he venido a vivir a un barrio [Orriols, a València], fiel reflejo de estas cifras. Es un barrio de las afueras, con múltiples necesidades, de estos que forman el cinturón triste de las grandes ciudades. Viven aquí alrededor de treinta mil personas, en su mayoría emigrantes, con un elevado índice de analfabetismo. La población escolar es de cuatro mil niños, entre seis y catorce años, y hay

76 «Boletín Informativo sobre la Objeción de Conciencia», WRI 7 de novembre de 1970. Enviat a la WRL, aquesta el va distribuir pels Estats Units; Subcarpeta I, carpeta 374, fons WRI, Arxiu de l'Internationaal Instituut voor Sociale Geschiedenis (IISG), Amsterdam.

77 Són les declaracions de Pepe Beunza en el Consell de Guerra que el va jutjar el 23 d'abril de 1971. Recollides a [autor@s Movimiento Objeción de Consciencia], En legítima desobediencia. Tres décadas de objeción, insumisión y antimilitarismo (Madrid: Traficantes de Sueños, 2002). 
una sola escuela nacional de quinientas plazas. Hasta los seis años, los niños se ven obligados a hacer de la calle su escuela, pues no existen grupos preescolares»..$^{7}$

La generació d'objectors següent, que va començar el 1975 a Can Serra, continuava en la mateixa línia de crítica al règim franquista, com es pot constatar en el comunicat que explicava per què es triava el barri per ferhi servei civil:

L'Hospitalet, con 350.000 habitantes y una densidad de 275 habitantes por hectárea, es una típica ciudad-dormitorio-colmena, fruto de una larga especulación privada de los constructores, permitida por el Ayuntamiento. Entre los casados mayores de 20 años, el 73 por ciento de las mujeres y el 54 por ciento de los hombres no tienen ni el certificado de Estudios Primarios. El déficit de plazas públicas gratuitas para la edad preescolar es del 91 por ciento, y de EGB el 64 por ciento, con sólo dos institutos de Enseñanza Media y una enseñanza profesional casi nula [...] El barrio de Can Serra [...] con 18.0oo habitantes, no cuenta con el mínimo de servicios necesarios. La densidad de población es de 800 habitantes por hectárea. Entre los servicios que la AV del barrio viene reclamando, se cuentan la necesidad de guarderías, escuelas, Formación Profesional, biblioteca, mercado, hogar de ancianos, centro cívico, parques, aparcamientos. ${ }^{79}$

Les dades que oferien els objectors, més enllà de l'exactitud, atenien una realitat incontestable de l'Espanya franquista; la proliferació de suburbis en les urbs, cosa que afectava certament l'Hospitalet de Llobregat, entre altres ciutats, i Can Serra, entre altres barris. Per tant, tornaven a situar l'acció dels objectors en unes coordenades crítiques evidents.

Entre aquests objectors continuava havent-hi una presència majoritària de motivacions pacifistes cristianes i no violents, com es pot veure en les cartes que els objectors van enviar als capitans generals de les regions militars a les quals estaven adscrits. Vicente Amurgos i Ovidio

78 «Carta de Beunza a l’Excmo. Sr. Capitán General. Valencia», 15 de novembre de 1971. Subcarpeta I, carpeta 374, fons WRI, IISG.

79 Fulletó. «La objeción es un derecho, no un delito», Barcelona, Edita Pax, febrer de 1976, 5. 
Bustillos, a més, havien estat seminaristes, per la qual cosa la motivació cristiana estava a flor de pell. Jesús Viñas era l'únic que sortia d'aquesta tendència argumentant la seva objecció des d'una «raíz humanística de base», però també amb alguna referència cristiana com les benaurances. En les cartes, els objectors usaven allegats de fraternitat per criticar idees com «frontera», «bandera» $\mathrm{i}$ «patria». Es referien també a qüestions com la cursa armamentística i les armes nuclears com a desenvolupament d'una espiral de violència destructiva que amenaçava la humanitat. Finalment, alguns d'ells exposaven crítiques polítiques i socials cap a la dictadura. Si Jesús Viñas assenyalava els «siete millones de analfabetos» i el subdesenvolupament social de la dictadura, Ovidio Bustillos recordava la repressió i la manca de llibertat: «al hablar de paz, no entiendo con esto la mera ausencia de guerra declarada. Mientras exista una mayoría silenciosa y silenciada, mientras existan en las cárceles personas privadas de libertad por el hecho de pensar distinto de quienes están en el poder». Vicente Amurgos, d'altra banda, afirmava que «mientras la sociedad viva alimentada de la violencia, donde unos pocos siguen manteniendo su poder sobre la violencia y el odio, y mientras en nuestra sociedad civilizada se siguen dando órdenes de pena de muerte, todos tenemos nuestra conciencia manchada de sangre»..$^{80}$ Òbviament, els afusellaments del 27 de setembre de 1975 eren molt propers en el temps i estaven presents en les paraules d'Amurgos.

A partir de l'experiència de Can Serra, l'aparició d'objectors de consciència no va cessar. A principis d'agost del 1976 hi havia cinc nous objectors en el projecte de Can Serra ${ }^{81}$ En la roda de premsa que van fer, van exposar com concebien la lluita pel reconeixement del dret a l'objecció de consciència en el mateix marc de lluites per les llibertats democràtiques. Van explicar que no eren militants de cap partit i, fins i tot, es queixaven de la poca implicació d'aquests grups en la qüestió. Cadascú presentava motivacions diverses. ${ }^{82}$ El sorgiment d'aquesta nova generació de Can Serra ja era una realitat des del gener del 1976, i no solament a

80 Ibídem.

81 «La Objeción de...».

82 Document del 1976 sobre els nous cinc objectors de Can Serra, carpeta 380, fons WRI, IISG. 
l'Hospitalet. A Bilbao, sis persones havien decidit fer el mateix a partir de l'estiu i no incorporar-se a files a primers de 1977, i una cosa similar també es reproduïa a Madrid. ${ }^{83}$ Mentre l'estiu del 1976 a Can Serra arribaren a ser fins a nou objectors, al barri d'Uretamendi, a Bilbao, n'hi hagué el mateix nombre i set al barri de Tetuán (Madrid). Però no van ser els únics: quatre persones més començaven un servei civil al barri de la Palma (Màlaga), tres a La Floresta (entre Tarragona i Reus) i dues més al collegi públic l'Estel de Vic. Tots els barris seleccionats pels objectors presentaven mancances similars a les de Can Serra. El barri de la Palma tenia un alt índex d'atur. De fet, els grups que des d'Andalusia es van vincular amb la no-violència i l'objecció de consciència es mostraren especialment sensibles amb l'atur. ${ }^{84}$

El fons de la qüestió era que cada vegada hi havia més joves que mostraven resistència al servei militar a través de l'objecció de consciència, de manera que s'anava ampliant la diversitat de motivacions i d'ideologies. Una part d'aquesta nova generació qüestionava, també, si la noviolència havia d'estar intrínsecament lligada a l'objecció de consciència. Una no-violència, recordem-ho, que durant aquesta primera etapa havia carregat de contingut teòric i ideològic la reivindicació d'aquesta opció. Des de llavors, però, les motivacions no violentes i religioses començaven a conviure amb altres d'«anarquizantes, socialistas e independientes», ${ }^{85}$ de manera que feien rebaixar el protagonisme de la no-violència i qüestionar-ne la innegociabilitat pràctica. D’aquesta manera, la resistència al servei militar es va convertir en el punt únic d'unió entre persones que, des de diverses motivacions i ideologies, es van associar contra la conscripció.

83 Informe de la WRI/IFOR Secretariats, «Spain Action Coordination», 15 de gener de 1976, C 379, fons WRI, IISG.

84 Aquesta particularitat del cas andalús la va reflectir John Paul Lederach en el seu llibre. J. P. LEDERACH, Els nomenats pacifistes. La noviolència a l'Estat espanyol (Barcelona: La Magrana, 1983), 98-102.

85 J. ViñaS, «La objeción de conciencia y el servicio civil», dins «Servicio Civil. Alternativa al servicio militar», Pax, 25 nov. 1976, caixa 79.4.2, Pavelló de la República, Barcelona. 


\section{Xarxa de suport $\mathrm{i}$ incidència política dels objectors}

Com hem vist, durant la dècada dels setanta l'objecció de consciència va irrompre en l'esfera pública. La qüestió es va afermar en l'agenda política, especialment quan va començar el procés de transició amb una proposta governamental el desembre del 1976, en què es reconeixia l'objecció de consciència per primera vegada, encara que fos de manera molt limitada. A més, el text constitucional confirmat el 1978 també admetia l'objecció com un dret (però no pas fonamental, tal com pretenien els objectors). D'altra banda, si durant la primera meitat d'aquesta dècada el nombre d'objectors no testimonis de Jehovà amb prou feines arribava a set, durant la segona meitat les persones objectores, moltes de les quals s'havien organitzat entorn de grups a les principals capitals espanyoles que es coordinaven a escala regional i estatal, superaven el centenar.

Malgrat aquest creixement considerable, la qüestió de l'objecció era poc coneguda i el nombre d'objectors continuava essent bastant reduït, fins i tot si comptem amb els testimonis de Jehovà. És molt difícil de saber el total d'objectors que donaven suport a l'objecció de consciència o que se la plantejaven quan els arribés el dia en què fossin cridats a files. L'única cosa que es pot saber és el nombre d'objectors empresonats. No obstant això, hi ha poques xifres sobre aquest tema. En dóna Jesús Jiménez en el seu estudi, que arriba fins al 1973; en total, $268 .{ }^{86} \mathrm{~A}$ partir d'aquell any, la quantitat d'objectors que anualment van anar sorgint poden comptar-se en els diversos volums de l'Anuario Estadístico Militar entre els anys 1974 i 1979, sota el títol «Negativa a la prestación del servicio militar», que mostra que prop de cent cinquanta joves per any es negaven a prestar el servei militar:

\begin{tabular}{cccccc}
1974 & 1975 & 1976 & 1977 & 1978 & 1979 \\
\hline 146 & 141 & 154 & 156 & 21 & 1 \\
\hline
\end{tabular}

Font: «Conjunto de ejércitos, clasificación de los condenados por ejércitos, en relación con la naturaleza de los delitos cometidos». Anuario Estadístico Militar (1970-1979), capítulo VIII Justicia, 1.

86 Jiménez, La objeción de..., 218. 
El descens ràpid que hi ha el 1978 s'explica per una ordre interna d'incorporació ajornada que el ministre de Defensa Gutiérrez Mellado va fer circular per les casernes el novembre del 1977, per la qual cosa qui reclamés l'excepció per objecció de consciència quedaria en situació d'«incorporación aplazada». La norma no va sortir publicada en el BOE, la qual cosa fa possible pensar que no fos coneguda arreu o que s'interpretés de manera arbitrària en cada centre de reclutament. Això explicaria que encara hi hagués persones jutjades per negar-se a incorporar-se a files.

D’aquesta manera, les úniques dades específiques són les dels objectors compresos entre el 1974 i el 1977. Abans del 1974 es pot fer un càlcul aproximat segons el delicte de «desobediencia» pel qual eren jutjats els objectors fins al 1973. La inclusió, el 1974, del delicte concret de «negativa a prestar el servicio militar» $\mathrm{i}$ la variabilitat de les xifres relatives al delicte de «desobediencia» fan que es pugui intuir la quantitat d'objectors per any. Per tant:

\begin{tabular}{lllllllllll} 
Any & 1970 & 1971 & 1972 & 1973 & 1974 & 1975 & 1976 & 1977 & 1978 & 1979 \\
\hline «Desobediencia» & 86 & 88 & 134 & 145 & 17 & 7 & 6 & 13 & 10 & 8 \\
\hline «Negativa a la prestación del servicio militar» & 146 & 141 & 154 & 156 & 21 & 1 \\
\hline
\end{tabular}

Font: «Conjunto de ejércitos, clasificación de los condenados por ejércitos, en relación con la naturaleza de los delitos cometidos». Anuario Estadístio Militar (1970-1979), capítulo VIII Justicia, 1.

Així, doncs, aproximadament 80 objectors es van negar a prestar servei d'armes els anys 1970 i 1971, mentre que entre 120 i 140 ho farien al llarg dels dos anys següents. En total, a l'entorn d'un miler de joves es van negar a fer el servei militar als anys setanta. La majoria eren testimonis de Jehovà, mentre que els que tenien motivacions catòliques, no-violentes, humanístiques i fins i tot polítiques van ser més aviat excepcionals fins a la segona meitat de la dècada.

Malgrat l'escàs nombre d'afectats, l'objecció de consciència va acabar aconseguint una repercussió política considerable. La causa principal té a veure amb les accions de la xarxa de suport que els objectors van aconseguir crear i la incidència d'aquesta en la imatge internacional del règim i del posterior procés de transició a la democràcia. La xarxa de 
suport dels objectors va començar amb Pepe Beunza i va mostrar-se especialment útil per fer créixer el moviment. Sense aquesta xarxa, hauria estat molt poc probable que l'acció d'uns quants joves arribés a tenir la incidència de què va gaudir i s'aconseguís desenvolupar la resistència al servei militar tal com es va fer a partir del 1975. Les obres que han abordat primer l'acció de Beunza i després la de Can Serra expliquen la formació d'aquesta xarxa i la seva importància, sobretot internament. No obstant això, no s'havia estudiat l'enorme implicació dels collectius internacionals, el grau de coordinació entre aquests i la incidència per pressionar les autoritats espanyoles. A més, aquesta solidaritat internacional va esdevenir fonamental per al suport, també anímic, dels mateixos objectors.

La gestació d'una xarxa de suport era fonamental, ja que, com Pepe Beunza sabia, la negativa a fer el servei militar suposava anar a la presó un nombre incert però important d'anys, de manera que a més es va preparar psicològicament i física. D’altra banda, Beunza entenia que el presidi havia de ser útil per pressionar el règim pel nombre d'objectors presos. La presó com a mitjà de pressió va ser usada pels objectors des de Beunza fins als insubmisos del final dels noranta; tots ells van assumir la repressió i la presó com a part integrant de l'estratègia contra l'Estat. Per això calia obtenir una àmplia opinió pública favorable a la causa dels represaliats: una empatia que es traduís en la deslegitimació cap a l'actitud del Govern. Per aconseguir-ho era necessari, també, teixir una extensa xarxa de suport nacional i internacional que respongués i pressionés quan calia i intentés aconseguir la màxima difusió possible de la qüestió. La xarxa de suport, per tant, va ser essencial per als objectors, de manera que a Espanya fou indispensable, com ja s'ha comentat, el suport del món catòlic proper als preceptes del concili II del Vaticà. Els sectors catòlics van ser el suport més decidit i compromès dins del territori espanyol, però no l'únic. El 1971, el Collegi d'Advocats de Barcelona era la sola institució espanyola que donava suport a les demandes dels objectors: es basava en el dret comparat amb altres països d'Europa i d'Amèrica, i se sumava així a la necessitat de regular l'objecció de consciència «de con- 
formidad con lo expresado por diversas instituciones internacionales»; $; 7$ citava Pax Christi, la Comissió de les Esglésies per a Assumptes Internacionals, la Federació Universal d'Associacions Cristianes d'Estudiants, el Congrés Mundial de la Joventut, la WRI, l'Assemblea Consultiva del Consell d'Europa, Amnistia Internacional, Justicia y Paz, la Comissió Internacional de Juristes, etc. Poc després s'hi afegiren els Grups d'Advocats Joves (Madrid), on destacaven les figures de Jaime Gil-Robles i Joaquín Ruíz-Giménez (ministre d'Educació de 1951 a 1956 i fundador de Cuadernos para el Diálogo), que va ser determinant perquè la qüestió arribés a altes esferes del règim. El desembre del 1970, Beunza es va reunir a Sant Cugat del Vallès amb una trentena de persones que es van comprometre a donar suport a la campanya per la reivindicació d'un estatut per als objectors de consciència. Aquestes persones havien de parlar amb polítics, periodistes i persones de l'Església. Els objectors fins i tot van recaptar suport dels militars de la Unió Militar Democràtica (UMD). El comandant José Altozano va ser arrestat el 1976 durant dos mesos per la defensa que va fer d'un objector. ${ }^{88}$

L'altre espai determinant de suport van ser les organitzacions internacionals. El contacte amb aquests grups va començar des del lligam amb la Communauté de l'Arche i les persones que s'hi relacionaven, fins a diverses agrupacions pacifistes i antimilitaristes, entre les quals cal destacar la IFOR i la WRI. Totes dues van tenir un paper clau en les campanyes internacionals de suport als objectors espanyols.

El contacte amb la WRI va iniciar-se per mitjà de qui era llavors secretari general de l'organització, Devi Prasad, que va interessar-se per la qüestió dels objectors espanyols i es va posar en contacte per correu postal amb persones vinculades a la no-violència a Espanya ${ }^{89}$ També l'Equip OC va començar a comunicar-se amb la WRI; d'una banda, per conèixer de

87 Illustre Collegi d’Advocats de Barcelona. Secció de Cultura, «Ponencia sobre la Objeción de Conciencia», Barcelona, 19 maig 1971, caixa 26, fons MOC, AEP, Barcelona.

88 «El arresto del capitán Altozano, ajeno a sus derechos como defensor de un objetor de conciencia», 23 de novembre de 1976. Consultat en l'Arxiu Linz de la Transición española, Centro de Estudios Avanzados en Ciencias Sociales. http://www.march.es/ceacs/biblioteca/proyectos/linz/documento.asp? reg $=\mathrm{r}-3135$.

89 Aquest volum de correspondència i d'intercanvi d'informació pot veure's en la subcarpeta I, carpeta 374, fons WRI, IISG. 
primera mà la feina d'aquesta organització, i, de l'altra, per informar de les accions a favor del reconeixement legal de l'objecció de consciència que es feien a l'Estat espanyol i per saber com s'abordava el tema en altres països. ${ }^{\circ}$ Amb aquesta presa de contacte es va generar una relació entre activistes espanyols i internacionals que va durar, com a mínim, fins a la dècada següent i que va servir per definir un canal d'informació i de solidaritat bidireccional.

L'ajuda internacional va ser fonamental, no tan sols per pressionar les autoritats, sinó també per oferir suport emocional i personal als objectors i al seu grup. En el cas de Pepe Beunza, la preparació de la seva acció va tenir com a objectiu arribar al major nombre de persones, associacions i institucions, sobretot europees, per implicar-les en la reclamació d'un estatut per a l'objecció de consciència. Amb aquest propòsit va treballar tot el 1970: va viatjar per Europa i va obtenir el suport de la Comissió Internacional de Juristes, la Lliga de Drets Humans de Suïssa i contactes directes amb l'Assemblea del Consell d'Europa. També va establir contacte amb organitzacions de tendències molt diverses però que tenien com a punt d'unió l'objecció, la no-violència i l'antimilitarisme. El setembre del $1970^{91}$ va començar la comunicació entre Beunza i Devi Prasad, que li transmeté l'interès de la WRI per la qüestió a Espanya. ${ }^{22}$ Fruit d'aquest contacte, la figura i la posterior acció de Beunza va ser coneguda a l'altre costat de l'Atlàntic. Mitjançant el vincle de la WRI, el tema de l'objecció de consciència a Espanya es va difondre pels cercles antimilitaristes i pacifistes dels Estats Units i va aparèixer en les revistes dels objectors d'aquell país, en l'Institute for the Study of Nonviolence, fundat per Joan Báez a Califòrnia, i difós també per la War Resisters League. ${ }^{93}$ En el cas de Joan Báez, la cantant va estar molt implicada personalment en la qüestió de l'objecció de consciència per l'empresonament del seu espòs,

90 Carta de l'Equip OC a la WRI, signa Andrés Duarte, 07/1971, subcarpeta III, carpeta 375, fons WRI, IISG.

91 Subcarpeta I, carpeta 374, fons WRI, IISG.

92 Carta de Devi Prasad a Pepe Beunza, 6 d'octubre de 1970, subcarpeta I, carpeta 374, fons WRI, IISG.

93 El primer article sobre el tema als EUA el va escriure el mateix Beunza amb el títol «Boletín Informativo sobre la Objeción de Conciencia». Fou publicat pel WRI el 7 de novembre de 1970 i enviat a la WRL, que el va distribuir pels EUA. Subcarpeta I, carpeta 374, fons WRI, IISG. 
David Harris: va organitzar un concert a Tolosa de Llenguadoc l'any 1976 per donar suport a la causa dels objectors espanyols, als quals va enviar els diners recaptats. ${ }^{94}$

Es van organitzar diverses formes d'efectuar la denúncia una vegada Beunza fos empresonat, com per exemple una llarga marxa de pacifistes europeus que va sortir de Ginebra organitzada per l'Equip OC a Espanya i amb la coordinació de la WRI i la IFOR. ${ }^{95}$ L'objectiu de l'acte era cridar l'atenció de l'opinió pública internacional i pressionar el Govern. La trobada pretenia arribar fins a la presó on era empresonat Beunza — finalment les autoritats franquistes van permetre que avancés fins a la frontera de Bourg-Madame.

El cas Beunza era considerat per les organitzacions internacionals (IFOR i WRI) l'inici del treball pacifista i antimilitarista a Espanya. ${ }^{6}$ Un suport que va ser clar i prioritari en l'agenda de la IFOR i la WRI durant la dècada dels setanta. ${ }^{97}$ L'enviament de cartes a les autoritats espanyoles, la recollida de signatures amb motiu dels objectors espanyols, com també protestes en ambaixades i consolats espanyols de les principals capitals europees i nord-americanes van ser accions freqüents de la xarxa d'organitzacions pacifistes i antimilitaristes per protestar per l'empresonament d'objectors espanyols, des de Beunza fins als de Can Serra. Totes aquestes operacions van implicar un exercici de coordinació important dels grups internacionals: es van produir reunions tant a fora com a dins del territori espanyol, es va gestar una cadena d'avisos per telèfon i correspondència, de manera que qualsevol novetat era ràpidament difosa pels principals grups pacifistes i antimilitaristes europeus. Les accions buscaven aconseguir el màxim grau de coordinació internacional, vincular personalitats reconegudes en la defensa dels objectors espanyols i denunciar-ne la situació. A més, s’incidia en la imatge externa del règim

94 Entrevista a Vicenç Fisas Armengol (24 abr. 2014).

95 Es va triar aquesta ciutat perquè hi havia la seu de l'ONU, el Tribunal de Drets de l'Home i perquè Suïssa no tenia reconegut el dret a l'objecció de consciència. Dins P. Oliver Olmo, La utopía insubmisa..., 72.

96 Carta de Pieter Eterman (IFOR) a Prasad, 24 maig 1971, subcarpeta II, carpeta 374, fons WRI, IISG.

97 Carta de Jean Fabre (WRI) a Pepe Beunza, 24 maig 1975, subcarpeta VII, carpeta 378, fons WRI, IISG. 
i del procés de transició iniciat després de la mort de Franco, de manera que es denunciava la manca de garanties dels drets civils i, per tant, qüestionaven la construcció de la nova democràcia a Espanya.

Potser un dels millors exemples de la incidència de l'acció internacional en el context espanyol pot ser el que va succeir el setembre del 1977. L'empresonament d'objectors durant els anys previs havia produït una gran reacció de la xarxa de suport dels objectors i, a més, els grups d'objecció havien crescut enormement (van implicar-hi moltes més persones i van fer créixer el nombre d'objectors potencials que podrien ser empresonats). Davant aquest panorama, i enmig d'un complex i tens procés de transició política, el govern d’Adolfo Suárez va promulgar el Reial decret 3011/1976, pel qual es mirava de regular l'objecció de consciència. Aquest text era fruit de la necessària implantació d'un cos legislatiu en el qual es reconeguessin els mateixos drets que en la resta dels països de la Comunitat Europea. Recordem que la integració en la CE era, sens dubte, una de les aspiracions més importants del Govern espanyol, i per això el nou Estat havia de tenir un cos legislatiu equiparable. De tota manera, en el cas de l'objecció de consciència, el reconeixement que atorgava aquesta disposició quedava molt lluny de les aspiracions dels objectors, que van començar una campanya per boicotejar-la i que va implicar noves detencions des del maig del 1977. La campanya, que va gaudir del suport del diputat del Partito Radicale italià Marco Pannella — va estar tretze dies en vaga de fam a Barcelona per les detencions dels objectors-, va tenir força èxit. L'acció fou secundada pel seu partit i per altres objectors que van acompanyar Pannella..$^{98}$ Com havia passat en el cas dels objectors de Can Serra, que denunciaren la manca de compromís real de l'Estat espanyol amb els drets civils, l'operació pretenia atacar una de les qüestions més sensibles del Govern: la imatge internacional. ${ }^{99}$ L'acció de Pannella

98 Sobre l'acció de Marco Pannella hi ha informació abundant en la caixa número 1 del fons MOC, AEP, Barcelona. També hi ha diverses notícies relacionades en l'arxiu en línia del Partito Radicale: http://www.radioradicale.it. S'hi poden trobar informacions sobre aquest tema entre el setembre i l'octubre del 1977.

99 Marco Pannella, un cop finalitzada la seva protesta, va denunciar personalment al Parlament Europeu les mancances relatives a l'objecció de consciència que es produïen a Espanya: http:// eur-lex.europa.eu/legal-content/EN/TXT/PDF/?uri=OJ:JOC_1978_042_R_0003_01\&rid=3. 
va ser fonamental per bloquejar el Reial decret i per alliberar els objectors que, sense acollir-s'hi, s'havien negat a fer el servei militar. El diputat italià no va aturar la seva protesta fins que el Govern espanyol no li va donar garanties de l'alliberament dels objectors empresonats, que seria l'amnistia del 6 d'octubre de 1977. L'ordre interna d'incorporació ajornada esmentada abans fou promulgada llavors amb la finalitat d'assegurar que no es produïssin noves detencions. No hi hagué nou projecte de llei fins al 1980, any en què el darrer govern de la UCD va començar la discussió d'un nou projecte que, finalment, no va arribar a bon port. Després d'això, la següent proposta legislativa sobre aquest tema va tenir lloc amb el PSOE al Govern. La proposta de llei dels socialistes per a l'objecció de consciència i la formulació d'una prestació social substitutòria tampoc no va satisfer els objectors, que van mostrar-s'hi en contra i van fer el possible per bloquejar-la. Per tant, fins al final del 1984 no hi va haver legislació sobre aquesta qüestió, i quan el Govern va tractar d'engegar a partir de 1988 la prestació social substitutòria, es va trobar novament amb l'oposició dels grups del MOC, els quals acumulaven una dècada de funcionament i inèrcia. L'única cosa que va operar en tot aquest temps va ser la incorporació ajornada.

Així doncs, l'objecció de consciència, malgrat que va ser un tema menor - en tota la dècada dels setanta, el nombre d'objectors no superava el miler de persones - va arribar a esdevenir una qüestió incòmoda per al franquisme al principi, va poder entrar en l'agenda de la Transició després i, finalment, va bloquejar les iniciatives legislatives que els objectors consideraven insuficients. Tot això gràcies a la creació d'una xarxa dinàmica de suport interna i externa, i a assumir la repressió i el presidi com una forma d'activar la mobilització, donar-la a conèixer i pressionar els diversos governs. 